R Karki

U Gurung

DK Baskota

Ganesh Man Singh Memorial

Academy (GMSMA) of ENT and HN

Studies, Tribhuvan University

Teaching Hospital, Maharajgunj,

Kathmandu.

Correspondence to

Dr. Reeba Karki,

Ganesh Man Singh Memorial

Academy of ENT and Head and

Neck Studies, TU Teaching Hospital,

Kathmandu, Nepal. Email:

karkireeba@hotmail.com.

\title{
Fibroma of Epiglottis
}

Fibroma is a benign tumor showing fibroblasts and collagen fibres. Fibroma in the larynx is a rare entity. We report a case of 38 years male with fibroma of epiglottis. The patient presented with change in voice and difficulty in breathing. On indirect laryngoscopy examination, there was smooth, pinkish, globular shaped mass arising from laryngeal surface of the epiglottis. The mass was excised perorally. Key words: fibroma, epiglottis, larynx, excision.

\section{INTRODUCTION:}

Fibroma is a benign tumour arising from mesenchymal tissue and is composed of fibrous or connective tissues. True laryngeal fibroma is a rare condition though the site of origin within the larynx can differ.

\section{CASE REPORT:}

A 38 years old male, presented to the ENT OPD with complaints of change in voice for 8 months and difficulty in breathing for 12 days. These symptoms increased in last 3 days before presentation. Indirect laryngoscopy revealed a smooth, globular shaped, pinkish mass arising from the laryngeal surface of epiglottis. The view of laryngeal inlet was obstructed by the mass and vocal cords status could not be appreciated. X-ray soft tissue neck, lateral view showed a soft tissue shadow at the level of hyoid (fig. 1). A clinical diagnosis of laryngeal cyst was

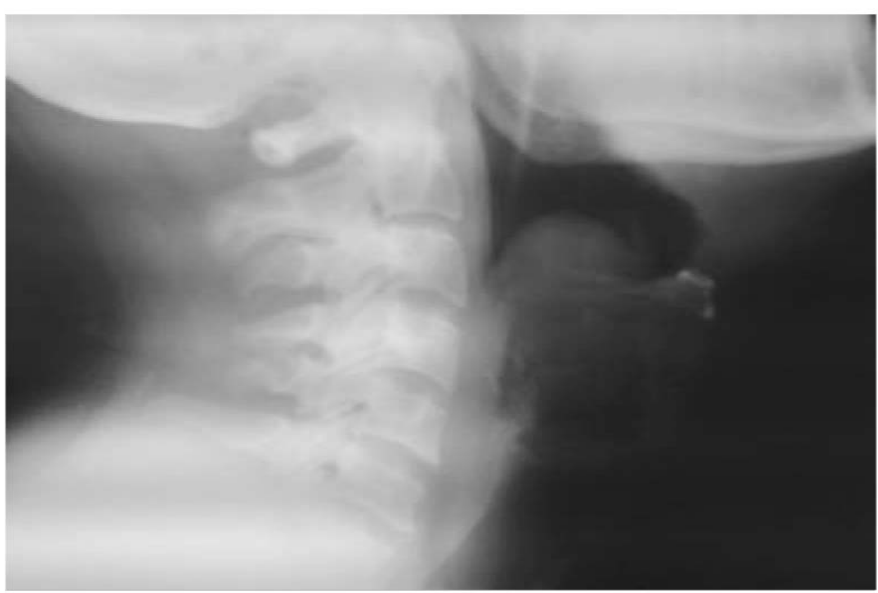

Fig.1: X-ray soft tissue neck, lateral view showing soft tissue shadow at the level of hyoid.
made.Since the patient presented with stridor, the patient underwent emergency tracheostomy under local anesthesia. He later underwent excision of the mass perorally under general anaesthesia. The mass was found to be arising from the laryngeal surface of epiglottis and was covering the laryngeal inlet. It was removed in toto and the base was cauterized. There was not much bleeding. The mass was $4 \times 3 \mathrm{cms}$ in size, firm and well encapsulated and on cut section was fleshy and homogenous. The specimen was sent for histopathological examination (Fig. 2, 3).

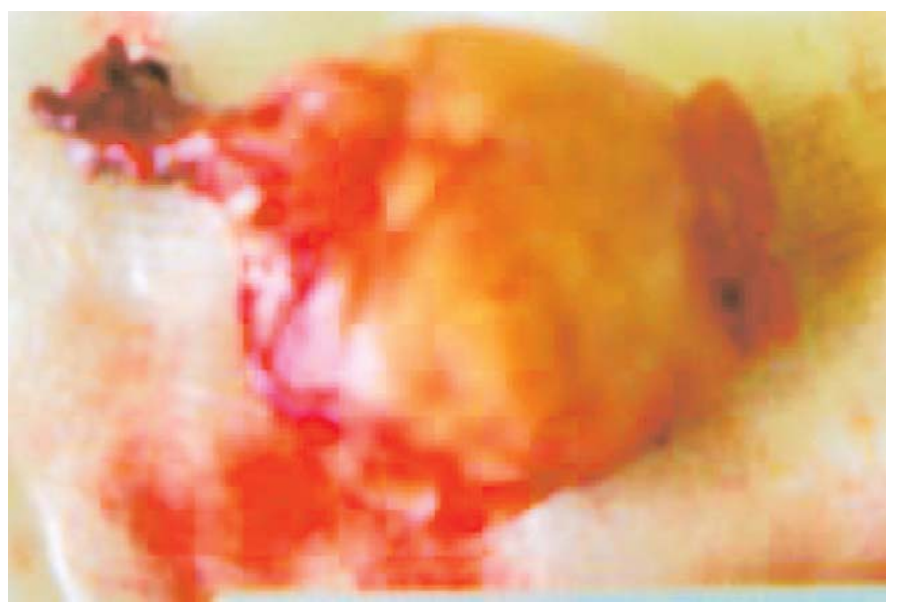

Fig.2: Specimen showing the mass

Microscopic examination showed spindle shaped cells with indistinct cytoplasm. Nuclei were relatively uniform, spindle to oval shaped and showed normochromasia. Some cells had wavy cytoplasm and nucleus. Mitosis and necrosis were absent. The final histopathological diagnosis was fibroma (Fig.4, 5). 


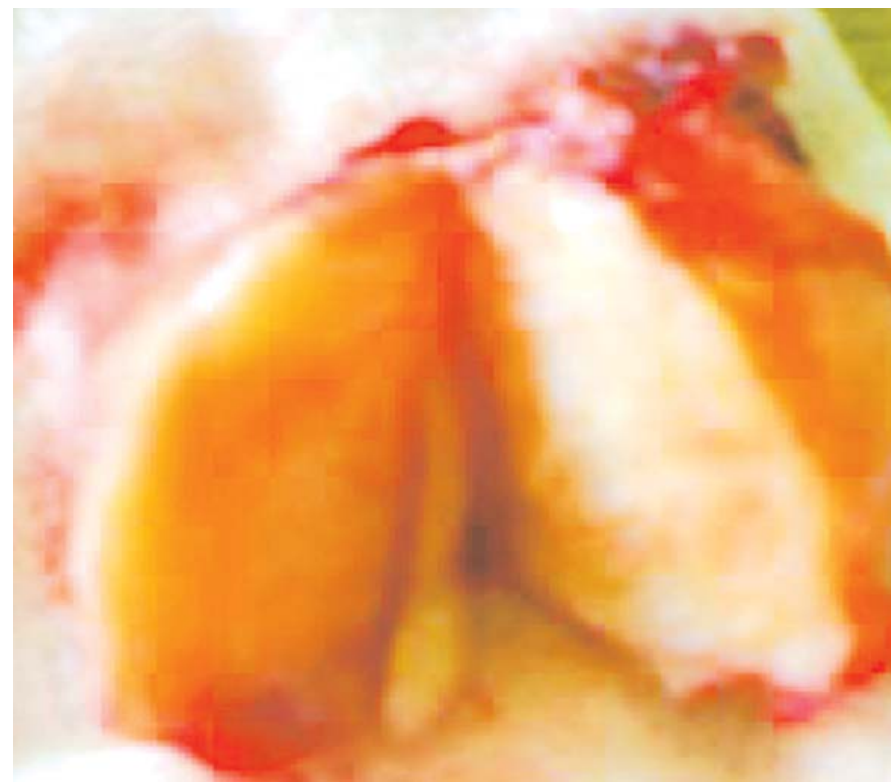

Fig. 3: Cut section of the same mass

\section{DISCUSSION:}

Fibroma of the larynx is a rare benign neoplasm. Stewart reported 9 cases of laryngeal fibroma over the period of 12 years. ${ }^{1}$ while Shaw reported 8 cases in 9 years durations. ${ }^{2}$ It commonly presents in the age group of 30-50 years. Our case also falls within this age range. There has been report of laryngeal fibroma in 15 years old male also. ${ }^{3}$ Symptoms include hoarseness, breathy voice, dyspnea, aspiration, dysphagia, pain, referred otalgia and hemoptysis. Diagnosis is based on direct or indirect visualization of the larynx, supplemented by X-ray, CT Scan , but the single most important diagnostic tool is a biopsy for histologic study of tumor tissue. Removal of the lesion restores voice, functional integrity of the laryngeal sphincter, and the airway. Depending upon the density of fibrous tissue and collagen content, laryngeal fibroma may be hard or soft. Hard fibroma (fibroma durum) consists of many fibres and few cells. Soft fibroma (fibroma molle) consists of many loosely connected cells and less fibroid tissue. Beside this there are other types of fibroma (angiofibroma, cystic fibroma, mixofibroma, cementoossifying fibroma, etc). Myxomatous degeneration occurring in fibroma makes the prognosis bad since it is always suggestive of malignant change so such case must be kept for close follow up.According to Ellis, small tumours can be removed endoscopically but larger ones require an external approach, fibroma extending beyond the laryngeal framework often require pharyngotomy or laryngofissure. ${ }^{4}$ Pertaining to this case, excision was done per orally using Boyle's Davis mouth gag since the tumour was small enough to and not needing external approach. A year after the intraoral excision of the laryngeal fibroma, there has been no recurrence.

\section{REFERENCES:}

1. Stewart J P. The histopathology of the benign tumor of the larynx. J Laryngol Otol 1957; 71: 718.

2. Shaw H J. Tumors of the larynx. In: John Ballantyne and John Groves. Scott-Brown‘s Otolaryngology. Vol 4. 3rd ed London: Butterworth;1971: 382

3. Gupta AK, Bhatia JN. Fibroma of the larynx. Ind J Oto Laryngol 1978; 30(40): 179.

4. Ellis M. Clinical Surgery, Ear, Nose and Throat. In: Charles Rob and Rodney Smith. Rob Smith. Vol 11.London: Butterworth; 1966: 245.
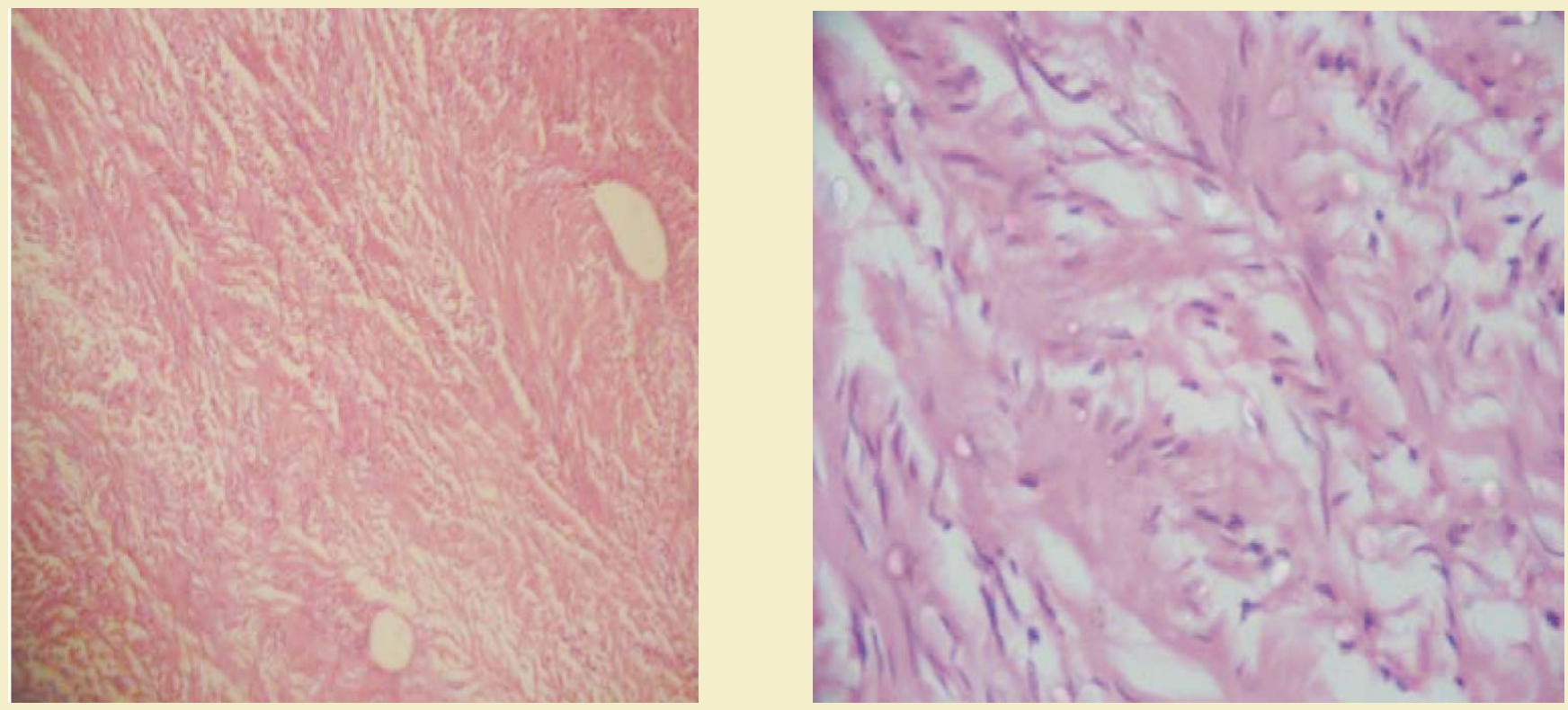

Fig. 4-5: Microphotograph showing many spindle-shaped cells with fine fibrils (haematoxylin and eosin x 450). 